\title{
Optimal Income Taxation with Tax Competition
}

\author{
Vilen Lipatov \\ Alfons Weichenrieder
}

CESIFo WORKING PAPER NO. 3108

CAtegory 1: Public Finance

JUNE 2010
An electronic version of the paper may be downloaded
- from the SSRN website:
- from the RePEc website:
- from the CESifo website:
www.SSRN.com
www.RePEc.org
www.CESifo-group.org/wp




\title{
Optimal Income Taxation with Tax Competition
}

\begin{abstract}
We introduce tax competition for mobile labor into an optimal-taxation model with two skill levels. We analyze a symmetric subgame-perfect Nash equilibrium of the game between two governments and two taxpayer populations. Tax competition reduces the distortion from the informational asymmetry and increases employment of the less productive individuals. When countries are heterogeneous, this effect is more pronounced in the smaller country.
\end{abstract}

JEL-Code: F22, H21.

Keywords: optimal income tax, migration, unemployment, tax competition, Leviathan government.

\author{
Vilen Lipatov \\ Goethe University \\ Grüneburgplatz 1 \\ 60323 Frankfurt am Main \\ Germany \\ Lipatov@em.uni-frankfurt.de
}

\author{
Alfons Weichenrieder \\ Goethe University \\ Frankfurt \\ Germany \\ a.weichenrieder@em.uni-frankfurt.de
}




\section{Introduction}

Recent years have seen a surge of research on tax competition. This is of little surprise, as in our globalized world the borders are becoming increasingly open; people, goods, and resources increasingly mobile; and government policies more interdependent. Nowadays, there is little doubt that a tax policy neglecting cross-border effects is no more than a (possibly convenient) abstraction.

A wide range of problems have been addressed within this blooming field, from tax-base erosion to redistribution and allocation of resources to coordination and harmonization proposals. Sinn (2003) provides an excellent overview of tax competition literature within a broader framework of systems competition. Capital tax competition has perhaps the longest tradition, as capital has early been recognized to be a mobile factor of production and, correspondingly, a most mobile tax base (for a seminal contribution, see Zodrow and Mieszkowski 1986). Income tax competition has also been analyzed, but mostly insofar as the mobile factors could affect it. Lately, mobility of individuals also has come into focus, especially in the context of European integration (e.g., Richter 2004).

Our paper contributes to this new strand of literature by merging tax competition for mobile labor with optimal-income-taxation approaches ${ }^{1}$. In a novel article, Simula and Trannoy (2010) analyze how migration possibilities affect the optimal taxation formula in a single country. Although our paper is also based on connecting optimal taxation with labor mobility, unlike Simula and Trannoy we focus on the effect of tax competition on the employment of low-skilled workers.

We augment a standard two-skill-level optimal-income-taxation model with the possibility of migration for high-skilled workers. In this framework governments compete for these workers and their taxes in a simple Hotelling setting.

The main result of our analysis is that opening the borders increases employment of the low-skill workers. Intuitively, competitive pressure lowers the tax on the mobile high-skill workers. This allows the government to reduce the distortion from taxing the low-skilled without violating the incentive

\footnotetext{
${ }^{1}$ Huber (1999) studies the effect of capital tax competition on the optimal income tax when labor is immobile. Osmundsen et al. (2000) analyze optimal income tax with mobile labor, but the asymmetric information in their model is about location preferences rather than productivity. Osmundsen et al. (1998) study a similar problem for firms.
} 
compatibility constraint. As a result, their employment increases. This is a clear, testable prediction that is robust to the choice of various objectives of the government and the relative size of the countries.

We also show that the smaller country lowers its tax on the high-skilled by more than the larger country does. This is consistent with the general intuition that the smaller entity is more aggressive in competition, as it has less revenue to lose from its own population, but a larger competitor's tax base to gain from lowering the tax.

There is a clear contribution of our result to the policy discussion about the vices and virtues of tax competition: despite a negative effect on tax revenues, it also has a positive effect on the employment of low-skilled workers. This may be particularly important for the countries with low efficiency of the government sector, as tax competition tames Leviathan governments and improves the resource allocation.

The rest of the paper is structured as follows. Section 2 contains the basic Leviathan model; in section 3 alternative government objectives are discussed; in section 4 the model with asymmetric equilibrium is analyzed; limitations and extensions are discussed in the conclusion.

\section{The Model}

\subsection{Closed economy}

We use as a benchmark Stiglitz's (1982) version of the Mirrlees (1971) model of income taxation, but introduce a different objective of the government. In a closed economy, individuals of measure 1 have identical preferences that can be represented by a utility function $u(x, y)$, where $x \geq 0$ is consumption and $0 \leq y \leq 1$ is the time worked. $u$ is a strictly concave, continuously differentiable function, strictly increasing in $x$ and strictly decreasing in $y$.

There are two types of individuals in the economy: those with high productivity $\theta_{H}$ constitute measure $\gamma$, and those with low productivity $\theta_{L}$ have correspondingly measure $1-\gamma ; \theta_{H}>\theta_{L}>0$. An individual of type $i$ provides $z_{i}=\theta_{i} y_{i}$ of labor while investing $y_{i}$ of her time.

The government cannot observe $\theta$, but it does observe income $z$ and chooses income taxes $\left.\left\{t_{L}, t_{H}\right\}\right|_{t_{i} \leq z_{i}}$ to maximize the tax revenue

$$
R=\gamma t_{H}+(1-\gamma) t_{L}
$$


subject to a satisfaction constraint $u_{L}, u_{H} \geq u_{0}$. This constraint makes it impossible for the living conditions of the poor to be set arbitrarily low and may be interpreted as a requirement of a modern welfare state.

In a separating equilibrium, the individual $i$ then chooses $\left(x_{i}, y_{i}\right)$ that maximizes $u(x, y)$ subject to $x_{i} \leq \theta_{i} y_{i}-t_{i}$, and corresponding incentive compatibility (IC) and participation constraints. For simplicity we assume that the utility thresholds that ensure participation are equal to $u_{0}$.

It is well known that the budget constraints, the IC constraint for the high type, and the participation constraint for the low type are binding in such problems (e.g., Stiglitz 1982). The individual optimization will result in setting consumption and time for the low type at the levels satisfying

$$
\begin{gathered}
x_{i}=\theta_{i} y_{i}-t_{i}, \\
\theta_{i}\left(1-t_{i}^{\prime}\right) u_{x}+u_{y}=0 .
\end{gathered}
$$

The Leviathan will then leave the less productive with their reservation utility, setting $t_{L}$ to satisfy

$$
u\left(z_{L}-t_{L}, z_{L} / \theta_{L}\right)=u_{0}
$$

and $t_{H}$ to satisfy

$$
u\left(z_{L}-t_{L}, z_{L} / \theta_{H}\right)=u\left(z_{H}-t_{H}, y_{H}\right)
$$

and the revenue maximization condition. The government will not find itself better off in a pooling equilibrium in our setting, as shown by Stiglitz (1982). Nothing guarantees, however, that the corner with $z_{L}=0$ is not hit.

Writing down the maximization explicitly (and in line with the literature), we can define the marginal tax rate as

$$
t_{i}^{\prime}=1+\frac{u_{y}}{\theta_{i} u_{x}} .
$$

We set up the Lagrangian $L=\gamma t_{H}+(1-\gamma) t_{L}+\mu\left(u\left(z_{L}-t_{L}, z_{L} / \theta_{L}\right)-u_{0}\right)+$ $\lambda\left(u\left(z_{H}-t_{H}, z_{H} / \theta_{H}\right)-u\left(z_{L}-t_{L}, z_{L} / \theta_{H}\right)\right)$ and denote for compactness $u^{L}:=$ $u\left(z_{L}-t_{L}, z_{L} / \theta_{L}\right) ; u^{H}:=\left(z_{H}-t_{H}, z_{H} / \theta_{H}\right) ; u^{H L}:=u\left(z_{L}-t_{L}, z_{L} / \theta_{H}\right)$. The corresponding FOCs are

$$
\begin{aligned}
& t_{L}: 1-\gamma-\mu u_{x}^{L}+\lambda u_{x}^{H L}=0, \\
& z_{L}: \mu\left(u_{x}^{L}+u_{y}^{L} / \theta_{L}\right)-\lambda\left(u_{x}^{H L}+u_{y}^{H L} / \theta_{H}\right)=0, \\
& t_{H}: \gamma-\lambda u_{x}^{H}=0, \\
& z_{H}: \lambda\left(u_{x}^{H}+u_{y}^{H} / \theta_{H}\right)=0 .
\end{aligned}
$$


The last equation immediately produces a "no distortion at the top" result: $u_{x}^{H}+u_{y}^{H} / \theta_{H}=0 \Longrightarrow t_{H}^{\prime}=0$. From quasiconcavity, $d x / d y=-u_{y} / u_{x}$ is an increasing function of $y$. Thus, as long as $x_{L}<x_{H}$, we have $-u_{y}^{H L} / u_{x}^{H L}<$ $-u_{y}^{H} / u_{x}^{H}$. Correspondingly, $u_{x}^{H L}+u_{y}^{H L} / \theta_{H}>u_{x}^{H}+u_{y}^{H} / \theta_{H}=0$, and from (1b) $u_{x}^{L}+u_{y}^{L} / \theta_{L}>0$, so that $t_{L}^{\prime}>0$.

Denote the optimal tax rates in the autarky case by $\left\{t_{L}^{a}, t_{H}^{a}\right\}$.

The appendix shows that for a sufficiently high level of $\gamma$ the low-skilled will find it optimal not to participate in the labor force $\left(z_{L}^{a}=0\right)$. In what follows we assume that $\gamma$ is sufficiently low.

\subsection{Open economy}

Suppose now we have two identical economies of the sort described above. Additionally, high-productivity individuals may migrate between countries in search of a better life. Low-productivity individuals are immobile. This is an extreme case of correlation between productivity and mobility decision, and we employ it for the sake of simplicity. Simula and Trannoy (2010) discuss why it seems reasonable to assume that higher-skilled workers are also more mobile. For example, skilled workers have better language skills and should have easier access to information on foreign countries.

Our high-productivity individuals differ in their propensity to migrate. Specifically, we assume that individuals populate the interval $[0,1]$ according to a continuously differentiable distribution function $F(a)$. Under this assumption we can use a Hotelling model for the analysis. Basically, our migration costs are similar in spirit to switching costs widely analyzed in the Industrial Organization literature (e.g., Farrell and Klemperer 2007). The utility of the high-productivity individual located at $a$ is $u(x, y)-c(a)$, where $c$ is a strictly increasing function with $c(0)=0$. Thus, we assume that utility is additively separable with respect to migration costs.

One caveat related to this analysis is that upon migration the government can observe the type of individual and thus impose a perfect-information tax on her (or any other tax conditioned upon the fact of migration and hence potentially different than the tax on the rest of population). However, we can exclude such behavior by postulating that the government must treat migrants and nonmigrants equally (and this is indeed the case in many countries that have antidiscrimination laws) for the sake of horizontal equity.

Given a pair of taxes $\left(t_{H}^{A}, t_{H}^{B}\right)$ in two countries, if $t_{H}^{A}<t_{H}^{B}$, all the individuals from country $\mathrm{B}$ with $a<\hat{a}: u\left(z_{H}^{A}-t_{H}^{A}, z_{H}^{A} / \theta_{H}\right)-c(\hat{a})=$ 
$u\left(z_{H}^{B}-t_{H}^{B}, z_{H}^{B} / \theta_{H}\right)$ will migrate to country A; and analogously for country B. Correspondingly, now the Leviathan will want to maximize ${ }^{2}$

$$
R^{A}=\gamma t_{H}^{A}\left(1+\int_{0}^{\hat{a}} d F(a)\right)+(1-\gamma) t_{L}^{A}
$$

subject to the participation constraint

$$
u\left(\theta_{L} y_{L}-t_{L}, y_{L}\right)=u_{0}
$$

the incentive compatibility constraint

$$
u\left(\theta_{H} y_{L}-t_{L}, y_{L}\right) \leq u\left(\theta_{H} y_{H}-t_{H}, y_{H}\right),
$$

which does not have to be binding any more, and individual rationality

$$
\theta_{i}\left(1-t_{i}^{\prime}\right) u_{x}+u_{y}=0
$$

The solution to this program for given $t_{H}^{B}$ will give us a best-response function for country A. Writing this up a bit more explicitly, we have

$$
\hat{a}=c^{-1}\left(u\left(z_{H}^{A}-t_{H}^{A}, z_{H}^{A} / \theta_{H}\right)-u\left(z_{H}^{B}-t_{H}^{B}, z_{H}^{B} / \theta_{H}\right)\right)
$$

and the Lagrangian $L=\gamma t_{H}\left(1+\int_{0}^{\hat{a}} d F(a)\right)+(1-\gamma) t_{L}+\mu\left(u\left(z_{L}-t_{L}, z_{L} / \theta_{L}\right)-u_{0}\right)+$ $\lambda\left(u\left(z_{H}-t_{H}, z_{H} / \theta_{H}\right)-u\left(z_{L}-t_{L}, z_{L} / \theta_{H}\right)\right)$, where $\lambda \geq 0$ and we omit superscript A for more parsimonious notation. The first order conditions are now

$$
\begin{aligned}
t_{L}: & 1-\gamma-\mu u_{x}^{L}+\lambda u_{x}^{H L}=0, \\
z_{L}: & \mu\left(u_{x}^{L}+u_{y}^{L} / \theta_{L}\right)-\lambda\left(u_{x}^{H L}+u_{y}^{H L} / \theta_{H}\right)=0, \\
t_{H}: & \gamma\left(1+\int_{0}^{\hat{a}} d F(a)-t_{H} f(\hat{a}) c^{-1 \prime}(.) u_{x}^{H}\right)-\lambda u_{x}^{H}=0, \\
z_{H}: & \gamma t_{H} f(\hat{a}) c^{-1 \prime}(.)\left(u_{x}^{H}+u_{y}^{H} / \theta_{H}\right)+\lambda\left(u_{x}^{H}+u_{y}^{H} / \theta_{H}\right)=0 .
\end{aligned}
$$

First, we can see that the conditions of the less productive are not affected by the migration possibility of the high-skilled. Second, the "no distortion at the top" result is still preserved, regardless of whether the IC constraint is

\footnotetext{
${ }^{2}$ To be concise, we do not explicitly consider the case with $t_{H}^{A}>t_{H}^{B}$. However, it is easy to see that our formulation remains valid in this complementary case, if we additionally define functions $c$ and $F$ on the interval $[-1,0]$ by $c(-a)=-c(a)$ and $F(-a)=-F(a)$.
} 
still binding. Indeed, as in the last expression $\gamma t_{H} f(\hat{a}) c^{-1 \prime}()+.\lambda$ is strictly positive, it is necessary that at the optimum $u_{x}^{H}+u_{y}^{H} / \theta_{H}=0$, that is, $t_{H}^{\prime}=0$. Third, the FOC with respect to $t_{H}$ has now an additional term $\int_{0}^{\hat{a}} d F(a)-t_{H} f(\hat{a}) c^{-1 \prime}(.) u_{x}^{H}$. If the IC constraint were not binding, the choice of the tax on high-productivity individuals would be a simple tradeoff between increasing the tax base and reducing the tax rate to maximize revenue. Otherwise, relaxing the IC constraint is an additional benefit of decreased tax:

$$
1+\int_{0}^{\hat{a}} d F(a)=t_{H} f(\hat{a}) c^{-1 \prime}(.) u_{x}^{H}+\frac{\lambda}{\gamma} u_{x}^{H} .
$$

The shadow value of the constraint is changed from $\gamma / u_{x}^{H}$ in autarky to $\gamma\left(1+\int_{0}^{\hat{a}} d F(a)\right) / u_{x}^{H}-\gamma t_{H} f(\hat{a}) c^{-1 \prime}($.$) in the open economy.$

It is not clear whether the IC constraint may become nonbinding, but in such a case the condition (3b) simplifies to $\mu\left(u_{x}^{L}+u_{y}^{L} / \theta_{L}\right)=0$, and we have no distortion at the bottom: $u_{x}^{L}+u_{y}^{L} / \theta_{L}=0$ as long as the participation constraint for the low-productivity individuals is binding. This is a remarkable result: in our model tax competition is a simple way to tame Leviathan, and it might even restore first-best solution in some cases.

Example 1 In the extreme case of no switching costs, Bertrand competition decreases the tax rates to zero. This is indeed an equilibrium if $u_{0} \geq$ $u\left(z_{H}\left(t_{H}=0\right), z_{H}(0) / \theta_{L}\right)$.

The best response of country A is defined by the equations (3a)-(3d) and (2). By the inverse function theorem, $c^{-1 \prime}()=.1 / c^{\prime}($.$) . We now look at a$ symmetric (subgame-perfect) Nash equilibrium, defined by the pair of best responses $t_{H}^{A}\left(t_{H}^{B}\right)$ and $t_{H}^{B}\left(t_{H}^{A}\right)$ such that $t_{H}^{A}=t_{H}^{B}=t_{H}^{o}$. The condition (3c) can be rewritten as

$$
t_{H}^{o}=\frac{c^{\prime}(0)}{f(0)}\left(\frac{1}{u_{x}^{H}}-\frac{\lambda}{\gamma}\right),
$$

and together with the conditions (3a)-(3d) it defines a symmetric Nash equilibrium in our model.

Notice that $c^{\prime}(0)$ reflects intensity of competition: for $c^{\prime}(0)=0$ there is no heterogeneity with respect to migration decision, so there is effectively Bertrand competition; for $c^{\prime}(0) \rightarrow \infty$ competition becomes ineffective, and we have the following lemma. 
Lemma 1 Consider autarky equilibrium tax rates $\left\{t_{L}^{a}, t_{H}^{a}\right\}$. For $c^{\prime}(0) \rightarrow \infty$, the unique symmetric equilibrium in the tax competition game converges to $t_{L}^{o}=t_{L}^{a}, t_{H}^{o}=t_{H}^{a}$.

Proof. Starting from autarky equilibrium values, from (1c) $\gamma-\lambda u_{x}^{H}=0$. The condition (3c) as a best response to autarky equilibrium in another country can be rewritten as $-\gamma t_{H} u_{x}^{H} f(0) / c^{\prime}(0)<0$, so there is an incentive to cut the tax, but this incentive vanishes in the limit of unbounded slope of the switching cost function.

Thus, the autarky equilibrium is a limiting case of open-economy equilibrium with no effective tax competition.

Proposition 1 Tax competition lowers the tax on the high-skilled, $t_{H}^{o}<t_{H}^{a}$.

Proof. From Lemma 1 we see that $t_{H}^{o} \neq t_{H}^{a}$. Now $t_{H}^{o}>t_{H}^{a}$ is not feasible: since the IC constraint is binding in autarky, a tax higher than in autarky on the "rich" is not possible without increasing the tax on the "poor". But if that were possible without violating their participation constraint, such an increase would have been also optimal in autarky. Thus, the only possible case is $t_{H}^{o}<t_{H}^{a}$.

Proposition 2 Tax competition increases employment of the low-skilled: $z_{L}^{o}>$ $z_{L}^{a}$.

Proof. From Proposition 1 we know that $t_{H}^{o}<t_{H}^{a}$. If the IC constraint is binding, along this constraint $d z^{H} / d z^{L}<0$ (see appendix). Since $d z^{H} / d t^{H}>$ 0 from the condition of no distortion at the top, $z_{L}^{o}>z_{L}^{a}$. If the IC constraint is not binding, from the condition of no distortion at the bottom, $z_{L}^{o}>z_{L}^{a}$.

The propositions assume existence of the equilibrium, and we establish it in the appendix.

An interesting policy-relevant observation obtains immediately: tax competition contributes to the employment of low-skilled labor, which is obviously a virtue. While such an increase does not improve the lot of the lowskilled, tax competition benefits the high-skilled at the expense of Leviathan. Conversely, tax coordination (autarky in our model) would increase tax revenue, but would be inferior to tax competition in terms of the employment and utility of the high-skilled ${ }^{3}$.

\footnotetext{
${ }^{3}$ It can be noted that tax competition is not necessarily welfare-improving in models of Leviathan governments. See Edwards and Keen (1996) for details.
} 


\section{Alternative objectives of the government}

\subsection{Rawlsian government}

Suppose now government is not interested in its own rents, but has Rawlsian preferences, that is, it wants to maximize the utility of the low-productivity individuals subject to some budget constraint. The corresponding Lagrangian is then

$$
\begin{aligned}
& L=u\left(z_{L}-t_{L}, z_{L} / \theta_{L}\right)+\lambda\left(u\left(z_{H}-t_{H}, z_{H} / \theta_{H}\right)-u\left(z_{L}-t_{L}, z_{L} / \theta_{H}\right)\right) \\
& +\mu\left(\gamma t_{H}\left(1+\int_{0}^{\hat{a}} d F(a)\right)+(1-\gamma) t_{L}\right) .
\end{aligned}
$$

We immediately see that the structure of the problem does not change, so the structure of the solution to it stays the same. The difference is that whereas Leviathan takes all the rents away from the "poor", the Rawlsian government, to the contrary, maximizes them. The FOCs are now

$$
\begin{aligned}
t_{L}: & \mu(1-\gamma)-u_{x}^{L}+\lambda u_{x}^{H L}=0, \\
z_{L}: & u_{x}^{L}+u_{y}^{L} / \theta_{L}-\lambda\left(u_{x}^{H L}+u_{y}^{H L} / \theta_{H}\right)=0, \\
t_{H}: & \mu \gamma\left(1+\int_{0}^{\hat{a}} d F(a)-t_{H} f(\hat{a}) c^{-1 \prime}(.) u_{x}^{H}\right)-\lambda u_{x}^{H}=0, \\
z_{H} & : \mu \gamma t_{H} f(\hat{a}) c^{-1 \prime}(.)\left(u_{x}^{H}+u_{y}^{H} / \theta_{H}\right)+\lambda\left(u_{x}^{H}+u_{y}^{H} / \theta_{H}\right)=0 .
\end{aligned}
$$

To see that this set of FOCs is equivalent to (3a)-(3d), divide them through by $\mu$ and re-denote $\mu_{1}=1 / \mu, \lambda_{1}=\lambda / \mu$. Then Lemma 1 and the no-distortion results go through. Proposition 1 still holds, because the Rawlsian government does not want to increase the tax on the "poor", and an increase in the tax on the "rich" is not possible without violating the IC constraint. Proposition 2 then remains intact, as it uses Proposition 1, the IC constraint (or no distortion at the bottom), and the "no distortion at the top" results.

Intuitively, it makes little difference whether the government wishes to tax the high-skilled to maximize its own rent or the utility of the poor. In both situations mobility of the high-skilled tends to ease the self-selection constraint that the government has to respect, allowing the poor to be less rationed on the labor market.

While in the Leviathan model tax competition has kept the utility of the poor constant, in the Rawlsian model their utility goes down and only the utility of the high-skilled goes up. 


\subsection{Utilitarian government}

Now consider the probably most popular formulation, in which the government wants to maximize the sum of the utility of the individuals. A problem here is that it is not clear whether the utility of new immigrants should enter the government's objective. Given that in reality obtaining citizenship is often a long and painful process, we assume that the government cares only about the established residents. Then the Lagrangian is

$L=\gamma u\left(z_{H}-t_{H}, z_{H} / \theta_{H}\right)+(1-\gamma) u\left(z_{L}-t_{L}, z_{L} / \theta_{L}\right)$

$+\lambda\left(u\left(z_{H}-t_{H}, z_{H} / \theta_{H}\right)-u\left(z_{L}-t_{L}, z_{L} / \theta_{H}\right)\right)+\mu\left(\gamma t_{H}\left(1+\int_{0}^{\hat{a}} d F(a)\right)+(1-\gamma) t_{L}\right)$.

The corresponding FOCs are

$$
\begin{aligned}
t_{L}: \mu(1-\gamma)-(1-\gamma) u_{x}^{L}+\lambda u_{x}^{H L}=0, \\
z_{L}:(1-\gamma)\left(u_{x}^{L}+u_{y}^{L} / \theta_{L}\right)-\lambda\left(u_{x}^{H L}+u_{y}^{H L} / \theta_{H}\right)=0, \\
t_{H}: \mu \gamma\left(1+\int_{0}^{\hat{a}} d F(a)-t_{H} f(\hat{a}) c^{-1 \prime}(.) u_{x}^{H}\right)-(\lambda+\gamma) u_{x}^{H}=0, \quad \text { (6c) } \\
z_{H}: \mu \gamma t_{H} f(\hat{a}) c^{-1 \prime}(.)\left(u_{x}^{H}+u_{y}^{H} / \theta_{H}\right)+(\lambda+\gamma)\left(u_{x}^{H}+u_{y}^{H} / \theta_{H}\right)=0(6 \mathrm{~d})
\end{aligned}
$$

This is not exactly equivalent to the previous problem, but we can immediately see that the "no distortion at the top" result survives, and so does the "no distortion at the bottom" in the case of a nonbinding IC constraint. The same is true for Lemma 1. In Proposition 1, the government has no incentive to increase taxes, as it cares about the utility of the "rich". Proposition 2 holds by the same reasoning as with Rawlsian government.

To sum up, our result about the effect of tax competition on employment of the "poor" is robust to the changes in the specification of government's objective function.

\section{Asymmetric countries}

Suppose now that the two countries we consider are of different size. Assume that whereas country B still has population of measure 1, country A has a population of measure $m>1$. Otherwise the countries are identical; in particular, $a$ is still distributed on a unit interval, only in the country A every point is $m$ times more populated.

The following two FOCs are changed for the Leviathan in country A (we consider here the more relevant case of $\left.t_{H}^{A}>t_{H}^{B}\right)$ : 


$$
\begin{aligned}
t_{L} & :(1-\gamma) m-\mu u_{x}^{L}+\lambda u_{x}^{H L}=0, \\
t_{H} & : \gamma\left(m-m \int_{0}^{\hat{a}} d F(a)-m t_{H} f(\hat{a}) c^{-1 \prime}(.) u_{x}^{H}\right)-\lambda u_{x}^{H}=0 .
\end{aligned}
$$

For country B, the only equation altered is

$$
t_{H}: \gamma\left(1+m \int_{0}^{\hat{a}} d F(a)-m t_{H} f(\hat{a}) c^{-1 \prime}(.) u_{x}^{H}\right)-\lambda u_{x}^{H}=0 .
$$

We see that, compared to the symmetric situation, the relative importance of tax competition terms is increased for the small country (B) and reduced for the large country (A). Notice that Propositions 1 and 2 do not hinge on the symmetry assumption, so they are still valid in the asymmetric setup. The existence proof, however, uses symmetry and has to be reestablished (see appendix).

Intuitively, the small country is more aggressive in tax competition, since it has more to gain (through attracting a foreign tax base) and less to lose from it (through reduced taxes from the home tax base). This is confirmed by the following proposition:

Proposition 3 In equilibrium of the asymmetric game, $t_{H}^{A}>t_{H}^{B}$.

Proof. Suppose the contrary is true. The case of $t_{H}^{A}=t_{H}^{B}$ is clearly inconsistent with the sets of FOC above. Consider the case of $t_{H}^{A}<t_{H}^{B}$. In equilibrium the gain of each country from marginally changing the tax rate should be zero.

Consider, for example, country B: $d R / d t_{H}=\gamma\left(1-\int_{0}^{\hat{a}} d F(a)-t_{H}^{B} f(\hat{a}) / c^{\prime}(\hat{a})\right)+$ $(1-\gamma) d t_{L} / d t_{H}=0$, where $d t_{L} / d t_{H}$ is taken along the binding constraints (participation, IC, and no distortion at the top), and hence must be identical for both countries. For the country A the change in revenue is then $d R / d t_{H}=\gamma\left(m+\int_{0}^{\hat{a}} d F(a)-t_{H}^{A} f(\hat{a}) / c^{\prime}(\hat{a})\right)$

$+(1-\gamma) m d t_{L} / d t_{H}=\gamma\left(m+\int_{0}^{\hat{a}} d F(a)-t_{H}^{A} f(\hat{a}) / c^{\prime}(\hat{a})\right)$

$-\gamma m\left(1-\int_{0}^{\hat{a}} d F(a)-t_{H}^{B} f(\hat{a}) / c^{\prime}(\hat{a})\right)$

$=\gamma\left((m+1) \int_{0}^{\hat{a}} d F(a)+\left(m t_{H}^{B}-t_{H}^{A}\right) f(\hat{a}) / c^{\prime}(\hat{a})\right)>0$, so country A is better off raising its tax. Thus, the case $t_{H}^{A}<t_{H}^{B}$ cannot be an equilibrium. 
While more aggressive behavior of the smaller country is a robust result in tax competition models (e.g., Haufler 2001, ch. 5), Proposition 3 allows us to formulate a new testable hypothesis: The positive effect of opening borders on employment of low-skilled workers is more pronounced in a small country.

\section{Conclusion}

We have analyzed tax competition in a simple optimal-income-taxation model. We show that the tax on the high-skilled decreases and employment of the low-skilled increases with respect to autarky. Our results are robust to a number of modifications concerning the government's objective function and symmetry of the two competing countries.

There are important limitations that we share with many optimal-taxation models. First, there is no account of capital, although it should be even more mobile than high-skilled labor. We focus on income taxation because we want to clearly identify the effect of combining competition with the principalagent framework that underlies optimal taxation models. Second, due to the simple linear production technology in one good economy, there are no general-equilibrium or trade effects of the wage changes that could lead to repercussions on the effects discussed.

We see several new directions for future research in the framework we have considered. Extensions of our model could assume countries that differ with respect to the national objective function or could allow for some mobility of low-skilled workers. We also hope that this paper will encourage empirical work on the labor market effects of migration opportunities. Based on our model, we would expect that tax competition for mobile high-skilled workers has more pronounced implications for low-skilled workers in small countries.

\section{Appendix}

\subsection{To Proposition 2}

Recall that $u_{x}>0, u_{y}<0, u_{x x}<0, u_{y y}<0$. From the participation constraint we have at the optimum 


$$
\frac{d z^{L}}{d t^{L}}=-\frac{u_{t}^{L}}{u_{z}^{L}}=\frac{u_{x}^{L}}{u_{x}^{L}+u_{y}^{L} / \theta_{L}}>1,
$$

as $u_{x}^{L}+u_{y}^{L} / \theta_{L}>0$, and from the condition of no-distortion at the top we have

$$
\frac{d z^{H}}{d t^{H}}=-\frac{-\left(u_{x x}^{H}+u_{y x}^{H} / \theta_{H}\right)}{u_{x x}^{H}+u_{x y}^{H} / \theta_{H}+\left(u_{y x}^{H}+u_{y y}^{H} / \theta_{H}\right) / \theta_{H}}>0
$$

if $u_{x y}^{H}<\min \left\{-\theta_{H} u_{x x}^{H},-u_{y y}^{H} / \theta_{H}\right\}$. From strict concavity we have $u_{x y}^{2}<$ $u_{x x} u_{y y}$, so this requirement is satisfied for a large class of concave functions. Moreover, $d z^{H} / d t^{H}<1$, under our assumption on the cross-derivative $u_{y x}^{H}$.

From the IC constraint,

$$
\frac{d z^{H}}{d z^{L}}=\frac{u_{x}^{H L}\left(1-t_{L}^{\prime}\left(z_{L}\right)\right)+u_{y}^{H L} / \theta_{H}}{u_{x}^{H}\left(1-t_{H}^{\prime}\left(z_{H}\right)\right)+u_{y}^{H} / \theta_{H}} .
$$

The denominator is negative, since $t_{H}^{\prime}\left(z_{H}\right)>1$. The numerator is negative if $u_{y}^{H L} u_{x}^{L} / \theta_{H}<u_{x}^{H L} u_{y}^{L} / \theta_{L}$ or $u_{x}^{L} / u_{y}^{L} \theta_{H}<u_{x}^{H L} / u_{y}^{H L} \theta_{L}$. Since $d y / d x$ is larger for the less productive, $u_{x}^{L} / u_{y}^{L}<u_{x}^{H L} / u_{y}^{H L}$, and the condition is indeed satisfied. We have

$$
\begin{aligned}
\frac{d z^{H}}{d z^{L}} & =\frac{u_{x}^{H L}\left(1-\frac{u_{x}^{L}+u_{y}^{L} / \theta_{L}}{u_{x}^{L}}\right)+u_{y}^{H L} / \theta_{H}}{u_{x}^{H}\left(1-\frac{u_{x x}^{H}+u_{x y}^{H} / \theta_{H}+\left(u_{y x}^{H}+u_{y y}^{H} / \theta_{H}\right) / \theta_{H}}{u_{x x}^{H}+u_{y x}^{H} / \theta_{H}}\right)+u_{y}^{H} / \theta_{H}}, \\
\frac{d z^{H}}{d z^{L}} & =\frac{u_{x}^{H L}\left(-\frac{u_{y}^{L} / \theta_{L}}{u_{x}^{L}}\right)+u_{y}^{H L} / \theta_{H}}{u_{x}^{H}\left(-\frac{\left(u_{y x}^{H}+u_{y y}^{H} / \theta_{H}\right) / \theta_{H}}{u_{x x}^{H}+u_{y x}^{H} / \theta_{H}}\right)+u_{y}^{H} / \theta_{H}} .
\end{aligned}
$$

Thus, the IC constraint combined with two other ones determines that $d z^{H} / d z^{L}<$ 0 .

It seems logical then that Leviathan will want to force the poor not to work and the rich to work as much as possible and to tax them as much as possible as well, but there are some limits to it:

Remark 1 For sufficiently high $\gamma$, a tax-revenue-maximizing allocation is characterized by $z_{L}^{a}=0$. 
Proof. Suppose $z_{L}^{a}>0$. Then a small reduction in $z_{L}$ will lead to an increase in $z_{H}$ that will keep IC constraint satisfied. From the participation and "no distortion at the top" constraints, that will also reduce $t_{L}$ and increase $t_{H}$ by amounts $d t^{L} / d z^{L}<1$ and $d t^{H} / d z^{H}>1$ correspondingly. Obviously, as long as $\gamma>\frac{d t^{L} / d z^{L}}{\left(d t^{H} / d z^{H}\right)\left(-d z^{H} / d z^{L}\right)+d t^{L} / d z^{L}}$, such a change will increase tax revenue without violating any constraint. Thus, at the optimum $z_{L}^{a}=0$.

We notice also that in situations with $z_{L}^{a}=0$ we must have $t_{L}^{a}<0$ from the participation constraint.

\subsection{On the Existence of Equilibrium}

\subsubsection{Symmetric model}

The existence of the equilibrium in our game hinges on two assumptions: (i) the conditions (3a)-(3d) and (2) define best responses; (ii) the intersection of these best responses is nonempty. For (i) it is necessary and sufficient that the conditions define an interior solution and second-order conditions are satisfied (they actually are, given our assumptions on the utility function and appropriate assumptions on the functions $c$ and $F$, plus any parameter restrictions that ensure an interior solution). For (ii) we have to study the best response on the interval $\left[0, t_{H}^{a}\right]$. By proposition 1 it is necessary and sufficient that the best response intersect the $45^{\circ}$ line on this interval. There are no discontinuities in our problem, so the best-response function must be continuous. As we have shown, $B R\left(t_{H}^{a}\right)<t_{H}^{a}$. On the other hand, $B R(0) \geq 0$, as a negative tax on the rich can not be revenue-maximizing. By continuity then there exists an intersection (or intersections) with the $45^{\circ}$ line on the interval $\left[0, t_{H}^{a}\right]$, and hence an equilibrium exists. Moreover, this equilibrium (or equilibria) is symmetric, because the best responses are identical.

\subsubsection{Asymmetric model}

We follow the same logic as for the symmetric situation. The appropriate parameter restrictions ensure that conditions from (i), modified correspondingly as in (7a)-(8), define best responses. For (ii), we need the two best responses to intersect. It is still true that $B R\left(t_{H}^{a}\right)<t_{H}^{a}$ and $B R(0) \geq 0$ for each country, so by continuity there exists at least one intersection on the interval $\left[0, t_{H}^{a}\right]$. 


\subsection{On the Uniqueness}

The symmetric equilibrium analyzed is unique whenever the system of equations $(3 \mathrm{a})-(3 \mathrm{~d}),(2)$, and $t_{H}^{A}=t_{H}^{B}$ has a unique solution.

\section{References}

[1] J. Edwards, M. Keen, Tax competition and Leviathan, European Economic Review 40 (1996), 113-134.

[2] J. Farrell and P. Klemperer, Coordination and lock-in: competition with switching costs and network effects, in: M. Armstrong, R. Porter (Eds.), Handbook of Industrial Organization, Elsevier, Volume 3, 2007, 19672072 .

[3] A. Haufler, Taxation in a Global Economy, Cambridge University Press, 2001.

[4] B. Huber, Tax competition and tax coordination in an optimum income tax model, Journal of Public Economics, 71 (1999), 441-458.

[5] J. Mirrlees, An exploration in the theory of optimum income taxation, The Review of Economic Studies, Vol. 38, No. 2 (1971), 175-208.

[6] P. Osmundsen, K.P. Hagen, G. Schjelderup, Internationally mobile firms and tax policy, Journal of International Economics, 45 (1998), 97-113.

[7] P. Osmundsen, G. Schjelderup, K. P. Hagen, Personal income taxation under mobility, exogenous and endogenous welfare weights, and asymmetric information, Journal of Population Economics 13 (2000), $623-637$.

[8] W. Richter, Delaying integration of immigrant labor for the purpose of taxation, Journal of Urban Economics 55 (2004), 597-613.

[9] H.-W. Sinn, The New Systems Competition, Blackwell Publishing, 2003.

[10] L. Simula and A. Trannoy, Optimal income tax under the threat of migration by top-income earners, Journal of Public Economics 94 (2010), $163-173$. 
[11] J. Stiglitz, Self-selection and Pareto efficient taxation, Journal of Public Economics, 17 (1982), 213-240.

[12] G. R. Zodrow, P. Mieszkowski, Pigou, Tiebout, property taxation and the underprovision of local public goods, Journal of Urban Economics 19 (1986), 356-370. 


\section{CESifo Working Paper Series}

for full list see www.cesifo-group.org/wp

(address: Poschingerstr. 5, 81679 Munich, Germany, office@cesifo.de)

3045 Bruno S. Frey and Lasse Steiner, Pay as you Go: A New Proposal for Museum Pricing, May 2010

3046 Henning Bohn and Charles Stuart, Population under a Cap on Greenhouse Gas Emissions, May 2010

3047 Balázs Égert and Rafal Kierzenkowski, Exports and Property Prices in France: Are they Connected?, May 2010

3048 Thomas Eichner and Thorsten Upmann, Tax-Competition with Involuntary Unemployment, May 2010

3049 Taiji Furusawa, Kazumi Hori and Ian Wooton, A Race beyond the Bottom: The Nature of Bidding for a Firm, May 2010

3050 Xavier Vives, Competition and Stability in Banking, May 2010

3051 Thomas Aronsson and Erkki Koskela, Redistributive Income Taxation under Outsourcing and Foreign Direct Investment, May 2010

3052 Michael Melvin and Duncan Shand, Active Currency Investing and Performance Benchmarks, May 2010

3053 Sören Blomquist and Laurent Simula, Marginal Deadweight Loss when the Income Tax is Nonlinear, May 2010

3054 Lukas Menkhoff, Carol L. Osler and Maik Schmeling, Limit-Order Submission Strategies under Asymmetric Information, May 2010

3055 M. Hashem Pesaran and Alexander Chudik, Econometric Analysis of High Dimensional VARs Featuring a Dominant Unit, May 2010

3056 Rabah Arezki and Frederick van der Ploeg, Do Natural Resources Depress Income Per Capita?, May 2010

3057 Joseph Plasmans and Ruslan Lukach, The Patterns of Inter-firm and Inter-industry Knowledge Flows in the Netherlands, May 2010

3058 Jenny E. Ligthart and Sebastian E. V. Werner, Has the Euro Affected the Choice of Invoicing Currency?, May 2010

3059 Håkan Selin, Marginal Tax Rates and Tax-Favoured Pension Savings of the SelfEmployed - Evidence from Sweden, May 2010 
3060 Richard Cornes, Roger Hartley and Yuji Tamura, A New Approach to Solving Production-Appropriation Games with Many Heterogeneous Players, May 2010

3061 Ronald MacDonald and Flávio Vieira, A Panel Data Investigation of Real Exchange Rate Misalignment and Growth, May 2010

3062 Thomas Eichner and Rüdiger Pethig, Efficient Management of Insecure Fossil Fuel Imports through Taxing(!) Domestic Green Energy?, May 2010

3063 Vít Bubák, Evžen Kočenda and Filip Žikeš, Volatility Transmission in Emerging European Foreign Exchange Markets, May 2010

3064 Leonid V. Azarnert, Après nous le Déluge: Fertility and the Intensity of Struggle against Immigration, May 2010

3065 William E. Becker, William H. Greene and John J. Siegfried, Do Undergraduate Majors or Ph.D. Students Affect Faculty Size?, May 2010

3066 Johannes Becker, Strategic Trade Policy through the Tax System, May 2010

3067 Omer Biran and Françoise Forges, Core-stable Rings in Auctions with Independent Private Values, May 2010

3068 Torben M. Andersen, Why do Scandinavians Work?, May 2010

3069 Andrey Launov and Klaus Wälde, Estimating Incentive and Welfare Effects of NonStationary Unemployment Benefits, May 2010

3070 Simon Gächter, Benedikt Herrmann and Christian Thöni, Culture and Cooperation, June 2010

3071 Mehmet Bac and Eren Inci, The Old-Boy Network and the Quality of Entrepreneurs, June 2010

3072 Krisztina Molnár and Sergio Santoro, Optimal Monetary Policy when Agents are Learning, June 2010

3073 Marcel Boyer and Donatella Porrini, Optimal Liability Sharing and Court Errors: An Exploratory Analysis, June 2010

3074 Guglielmo Maria Caporale, Roman Matousek and Chris Stewart, EU Banks Rating Assignments: Is there Heterogeneity between New and Old Member Countries? June 2010

3075 Assaf Razin and Efraim Sadka, Fiscal and Migration Competition, June 2010

3076 Shafik Hebous, Martin Ruf and Alfons Weichenrieder, The Effects of Taxation on the Location Decision of Multinational Firms: M\&A vs. Greenfield Investments, June 2010 
3077 Alessandro Cigno, How to Deal with Covert Child Labour, and Give Children an Effective Education, in a Poor Developing Country: An Optimal Taxation Problem with Moral Hazard, June 2010

3078 Bruno S. Frey and Lasse Steiner, World Heritage List: Does it Make Sense?, June 2010

3079 Henning Bohn, The Economic Consequences of Rising U.S. Government Debt: Privileges at Risk, June 2010

3080 Rebeca Jiménez-Rodriguez, Amalia Morales-Zumaquero and Balázs Égert, The VARying Effect of Foreign Shocks in Central and Eastern Europe, June 2010

3081 Stephane Dees, M. Hashem Pesaran, L. Vanessa Smith and Ron P. Smith, Supply, Demand and Monetary Policy Shocks in a Multi-Country New Keynesian Model, June 2010

3082 Sara Amoroso, Peter Kort, Bertrand Melenberg, Joseph Plasmans and Mark Vancauteren, Firm Level Productivity under Imperfect Competition in Output and Labor Markets, June 2010

3083 Thomas Eichner and Rüdiger Pethig, International Carbon Emissions Trading and Strategic Incentives to Subsidize Green Energy, June 2010

3084 Henri Fraisse, Labour Disputes and the Game of Legal Representation, June 2010

3085 Andrzej Baniak and Peter Grajzl, Interjurisdictional Linkages and the Scope for Interventionist Legal Harmonization, June 2010

3086 Oliver Falck and Ludger Woessmann, School Competition and Students' Entrepreneurial Intentions: International Evidence Using Historical Catholic Roots of Private Schooling, June 2010

3087 Bernd Hayo and Stefan Voigt, Determinants of Constitutional Change: Why do Countries Change their Form of Government?, June 2010

3088 Momi Dahan and Michel Strawczynski, Fiscal Rules and Composition Bias in OECD Countries, June 2010

3089 Marcel Fratzscher and Julien Reynaud, IMF Surveillance and Financial Markets - A Political Economy Analysis, June 2010

3090 Michel Beine, Elisabetta Lodigiani and Robert Vermeulen, Remittances and Financial Openness, June 2010

3091 Sebastian Kube and Christian Traxler, The Interaction of Legal and Social Norm Enforcement, June 2010

3092 Volker Grossmann, Thomas M. Steger and Timo Trimborn, Quantifying Optimal Growth Policy, June 2010 
3093 Huw David Dixon, A Unified Framework for Using Micro-Data to Compare Dynamic Wage and Price Setting Models, June 2010

3094 Helmuth Cremer, Firouz Gahvari and Pierre Pestieau, Accidental Bequests: A Curse for the Rich and a Boon for the Poor, June 2010

3095 Frank Lichtenberg, The Contribution of Pharmaceutical Innovation to Longevity Growth in Germany and France, June 2010

3096 Simon P. Anderson, Øystein Foros and Hans Jarle Kind, Hotelling Competition with Multi-Purchasing: Time Magazine, Newsweek, or both?, June 2010

3097 Assar Lindbeck and Mats Persson, A Continuous Theory of Income Insurance, June 2010

3098 Thomas Moutos and Christos Tsitsikas, Whither Public Interest: The Case of Greece's Public Finance, June 2010

3099 Thomas Eichner and Thorsten Upmann, Labor Markets and Capital Tax Competition, June 2010

3100 Massimo Bordignon and Santino Piazza, Who do you Blame in Local Finance? An Analysis of Municipal Financing in Italy, June 2010

3101 Kyriakos C. Neanidis, Financial Dollarization and European Union Membership, June 2010

3102 Maela Giofré, Investor Protection and Foreign Stakeholders, June 2010

3103 Andrea F. Presbitero and Alberto Zazzaro, Competition and Relationship Lending: Friends or Foes?, June 2010

3104 Dan Anderberg and $\mathrm{Yu}$ Zhu, The Effect of Education on Martial Status and Partner Characteristics: Evidence from the UK, June 2010

3105 Hendrik Jürges, Eberhard Kruk and Steffen Reinhold, The Effect of Compulsory Schooling on Health - Evidence from Biomarkers, June 2010

3106 Alessandro Gambini and Alberto Zazzaro, Long-Lasting Bank Relationships and Growth of Firms, June 2010

3107 Jenny E. Ligthart and Gerard C. van der Meijden, Coordinated Tax-Tariff Reforms, Informality, and Welfare Distribution, June 2010

3108 Vilen Lipatov and Alfons Weichenrieder, Optimal Income Taxation with Tax Competition, June 2010 